\title{
Improving clean water access for fishermen communities in Khaidir village environment 6 Nelayan Indah sub-district Medan Labuhan district Medan city
}

\author{
Surya Dharma ${ }^{1 *}$, Irnawati Marsaulina ${ }^{1}$ \\ ${ }^{1}$ Faculty of Public Health, Universitas Sumatera Utara, Medan - Indonesia \\ *Email: surya582003@yahoo.com
}

\begin{abstract}
The Community Service Program (PPM) aims to improve the knowledge and skills of coastal communities through water filter science and technology by using media consisting of quartz sand, 1-3 cm diameter gravel, activated charcoal and alum. Long-term goals can improve the quality of life and avoid people from waterborne diseases so that the degree of public health improves. This community service was carried out in Kampung Khaidir Lingkungan 6 Kelurahan Nelayana Indah, Medan Labuhan District, Medan City. In order to achieve these objectives several stages of activities are carried out. First is the initial survey activity to find out the location for the drilling of the well that will be used by the local community. The second stage is to build a Bor well unit. The third stage socializes the use of Bor wells access to clean water and changes people's behavior so they behave in a clean and healthy life. This community service program is carried out within 6 months. The targets and outcomes of this program are: (1). Access to Bor wells Clean Water. The community masters the science and technology of making Bor wells to be a source of water that meets health requirements as well as meeting the need for clean water for 22 Fishermen Families in Kampung khaidir Neighborhood 6 Kelurahan Indah Fishermen District Medan Labuha District. (2). The Clean and Healthy Life Behavior of the community increases based on the posttest and observation of the living environment. (3). The decreasing prevalence of diseases transmitted through water media such as diarrhea, skin diseases so that the degree of public health increases and community productivity also increases.
\end{abstract}

Keywords: Coastal Ecosystems, Larva Habitat, Mosquitoes, Control

\begin{abstract}
Abstrak
Kelompok Program Pengabdian Masyarakat (PPM) ini bertujuan untuk meningkatkan pengetahuan dan keterampilan masyarakat wilayah pesisir melalui iptek filter air dengan menggunakan media yang terdiri dari pasir kuarsa, kerikil diameter 1-3 cm, arang aktif dan tawas. Tujuan jangka panjang dapat meningkatkan kualitas hidup dan terhindarnya masyarakat dari penyakit yang ditularkan oleh air sehingga derajat kesehatan masyarakat meningkat. Pengabdian masyarakat ini dilaksanakan di Kampung Khaidir Lingkungan 6 Kelurahan Nelayana Indah Kecamatan Medan Labuhan Kota Medan. Dalam rangka mencapai tujuan tersebut dilaksanakan beberapa tahapan kegiatan. Pertama adalah kegiatan survai awal untuk mengetahui lokasi untuk pembuatan sumur Bor yang akan dipergunakan masyarakat setempat. Tahap kedua adalah membangun satu unit sumur Bor. Tahap ketiga mensosialisasikan penggunaan akses air bersih sumur Bor dan merubah perilaku masyarakat supaya berperilaku hidup bersih dan sehat. Program pengabdian masyarakat ini dilaksanakan dalam waktu 6 bulan. Target dan luaran dari program ini adalah: (1). Akses Air Bersih sumur Bor. Masyarakat menguasai Iptek pembuatan sumur Bor menjadi sumber air yang memenuhi syarat kesehatan serta terpenuhinya kebutuhan air bersih bagi 22 Keluarga Nelayan di Kampung khaidir Lingkungan 6 Kelurahan Nelayan Indah Kecamatan Medan Labuha. (2). Prilaku Hidup Bersih dan Sehat masyarakat meningkat berdasarkan postest dan observasi lingkungan tempat tinggal. (3). Menurunnya prevalensi penyakit yang ditularkan melalui media air seperti diare, penyakit kulit sehingga derajat kesehatan masyarakat meningkat dan produktivitas masyarakat juga meningkat.
\end{abstract}

Kata Kunci: Ekosistem Pantai, Habitat Larva, Nyamuk, Pengendalian 


\section{PENDAhuluan}

\subsection{Analisis Situasi}

Kelurahan Nelayan Indah Kecamatan Medan Labuhan merupakan daerah tepi pantai yang para penduduknya belum mempunyai akses air bersih untuk keperluan sehari-hari. Masyarakat mendapatkan air bersih dengan cara membeli dari penjual air yang dating ke pemukiman mereka. Tingginya harga air yang dijual sehingga masyarakat membeli hanya untuk kebutuhan utama masak dan minum.

Masyarakat Kelurahan Nelayan Indah Kecamatan Medan Labuhan umumnya penduduknya bekerja sebagai nelayan tradisional. Jumlah keluarga yang belum mempunyai akses air bersih sebanyak $22 \mathrm{KK}$. Sebagai nelayan tradisional maka penghasilannya tergolong tidak terlalu tinggi sehingga secara ekonomi dapat digolongkan sebagai masyarakat menengah kebawah maka mereka tidak mampu membuat sumur bor untuk menyediakan sumber air bersihnya yang memenuhi syarat air minum yang sehat.

Air berperan penting dalam meningkatkan derajat kesehatan masyarakat, karena air dapat menjadi media dari berbagai macam penularan penyakit. Seperti telah kita ketahui bahwa penyakit infeksi saluran pencernaan adalah penyakit yang paling banyak terjadi di Indonesia. Dengan penyediaan air bersih baik itu dari segi kualitas maupun kuantitasnya maka penyakit infeksi saluran cerna dengan keluhan utama diare dapat ditekan seminimal mungkin.

\subsection{Permasalahan Mitra}

Sebagai daerah pesisir pantai, sulit sekali mendapatkan sumber air bersih dari air tanah ataupun air permukaan di Kelurahan Nelayan Indah Kecamatan Medan Labuhan. Pebuatan sumur bor memerlikan biaya yang relatif mahal sehingga masyarakat mengharapkan adanya bantuan iptek yang dapat menyediakan sumber air bersih dari sumur bor.

\section{METODE PELAKSANAAN}

\subsection{Solusi yang ditawarkan (Metode penerapan IPTEKS)}

Setelah melihat dan menganalisis permasalahan yang dimiliki oleh mitra, maka solusi yang dapat ditawarkan kepada kelompok masyarakat ini adalah :

1. Promosi kesehatan tentang Prilaku Hidup Bersih dan Sehat (PHBS) dan menciptakan lingkungan yang saniter kepada seluruh masyarakat.

2. Dari penyuluhan ini diharapkan masyarakat meningkat pengetahuan tentang PHBS dan melaksanakan dalam kehidupan sehari-hari berupa kebersihan diri, sanitasi dasar sesuai konsep kesehatan dan menciptakan lingkungan yang saniter bebas dari sumber pencemaran.

3. Pembangunan sarana air bersih berupa 1 unit sumor bor kedalaman 90 meter dengan pompa kompresor dan dinamo yang digerakkan oleh tenaga listrik untuk kebutuhan air bersih 10 kepala keluarga.

4. Dengan tersedianya akses air bersih yang memenuhi syarat kesehatan maka masyarakat dapat melaksanakan prilaku hidup bersih dan sehat sesuai dengan konsep sanitasi.

5. Mengganti pompa kompresor dan dynamo penggerak yang rusak pada 1 unit sumur bor yang tidak berfungsi.

6. Masyarakat yang terdiri dari 10 kepala keluarga akan mendapat akses air bersih kembali dari sumur bor yang telah diganti komponennya dengan alat kompresor dan dynamo penggerak yang terbaru 


\subsection{Metode Pendekatan}

Metode pendekatan yang dipergunakan dalam program ini adalah metode partisipatif melalui kelompok maupun individu. Pendampingan dan koordinasi kepada mitra akan dilakukan dengan memberikan penyuluhan promosi kesehatan metode ceramah dan diskusi. Pemantauan terhadap mitra dilakukan sebulan sekali atau disesuaikan dengan kebutuhan mitra. Mitra diberikan sarana fasilitas akses air bersih dan diberikan motivasi dan sharing informasi agar mitra tetap merawat peralatan yang diberikan serta menciptakan lingkungan yang bersih dan sehat secara berkesinambungan serta mengimplemen-tasikan prilaku hidup bersih dan sehat.

\section{HASIL DAN PEMBAHASAN}

Pengabdian pada masyarakat yang sudah dilakukan pada masyarakat Kampung khaidir Lingkungan 6 Kelurahan Nelayan Indah Kecamatan Medan Labuhan Kota Medan yang didanai oleh Dana Non PNPB USU Tahun 2019 dilakukan 2 kali kegiatan atau dua tahap. Untuk kunjungan pertama adalah melaksanakan promosi kesehatan dengan presentase yang dilakukan oleh nara sumber pada tanggal 28 juli 2019 tentang Prilaku Hidup Bersih dan Sehat (PHBS) dan menciptakan lingkungan yang saniter. Tahap kedua adalah pembangunan fasilitas sarana air bersih berupa pemberian bantuan 1 unit sumor bor kedalaman 90 meter dengan pompa kompresor dan dinamo yang digerakkan oleh tenaga listrik untuk kebutuhan air bersih 10 kepala keluarga serta mengganti pompa kompresor dan dynamo penggerak yang rusak pada 1 unit sumur bor yang tidak berfungsi.

\subsection{Tahap I Promosi Kesehatan Prilaku Hidup Bersih dan Sehat (PHBS) dan Menciptakan Lingkungan yang Saniter}

Kegiatan Promosi Kesehatan Prilaku Hidup Bersih dan Sehat (PHBS) dan menciptakan lingkungan yang saniter dilaksanakan pada hari Sabtu tanggal 28 juli 2019 jam $09.00-12.30$ WIB bertempat di Aula Kampung khaidir Lingkungan 6 Kelurahan Nelayan Indah Kecamatan Medan Labuhan dan dihadiri oleh $20 \mathrm{KK}$ dan Tokoh Masyarakat Kampung Khaidir Lingkungan 6 di Kelurahan Nelayan Indah Kecamatan Medan Labuhan.

Kegiatan Promosi Kesehatan ini dalam bentuk presentasi menggunakan slide, diikuti dengan sesi tanya jawab (diskusi) yang masyarakat sangat antusias untuk mengajukan pertanyaan tentang kesehatan dan lingkungan serta ditutup dengan komitmen masyarakat untuk melaksanakan Prilaku Hidup Bersih dan Sehat (PHBS) dan menciptakan lingkungan yang saniter.

\subsection{Tahap II Pembangunan Fasilitas Sarana Air Bersih}

Kegiatan pembangunan fasilitas sarana air bersih dimulai pada tanggal 29 Juli 2019 dan selesai pada tanggal 30 Juli 2019. Bentuk kegiatannya adalah membuat 1 unit sumor bor kedalaman 90 meter, air dikeluarkan dengan menggunakan pompa kompresor dan dinamo yang digerakkan oleh tenaga listrik.

Pada tahap ini juga dilakukan penggantian pompa kompresor dan dynamo penggerak yang rusak pada 1 unit sumur bor yang tidak berfungsi. Air dapat didistribusikan kembali kepada $10 \mathrm{KK}$ yang dalam beberapa waktu yang lalu tidak lagi mendapatkan air dari sumur bor tsb. Kualitas air yang keluar secara fisik adalah baikkarena bersih tidak berwarna, tidak berbau dan tidak berasa sehingga dapat langsung digunakan oleh masyarakat.

Masyarakat sangat bersyukur dan senang sekali karena air bersih yang merupakan salah satu kebutuhan utama manusia untuk dapat hidup bersih dan sehat dan mereka berjanji akan terus merawat peralatan sumur bor ini secara berkala agar tetap berfungsi secara baik.

Program pengabdian dengan melakukan sosialisasi penggunaan akses air bersih sumur bor, pelatihan pembuatan filter air dapat menambah wawasan dan pengetahuan masyarakat dalam Berperilaku hidup bersih dan sehat. Rencana pada tahapan selanjutnya akan dilakukan pemantauan 
pemeriksaan peralatan sumur bor dan kelancaran distribusi akses air bersih dari sumur bor kepada masyarakat, pemantauan dan pembinaan sanitasi lingkungan sebagai implementasi PHBS dalam masyarakat.

Kegiatan kesinambungan program ini salah satunya ditekankan pada kesinambungan Perilaku Hidup Bersih dan Sehat (PHBS), dimana sebelumnya terdapat sosialisasi PHBS untuk meningkatkan derajat kesehatan masyarakat dengan pengetahuan pentingnya hidup bersih. Program pengabdian ini sebenarnya ditujukan terlebih pada daerah yang sarana sanitasinya tidak memadai, namun karena daerah pengabdian masyarakat di kampung khaidir lingkungan 6 kelurahan nelayan indah kecamatan Medan Labuhan memiliki sanitasi yang kurang layak, kegiatan PHBS dilakukan dalam bentuk penyuluhan dan pembangunan sarana sanitasi. Kesinambungan program PHBS terlihat dengan semakin banyaknya masyarakat yang hidup sehat walaupun sebelumnya sudah melakukan hidup sehat dan bersih, terlebih di kelurahan Nelayan indah kecamatan Medan Labuhan., setelah adanya program sudah jarang masyarakat yang BAB sembarangan.

\section{KESIMPULAN}

Promosi kesehatan Perilaku Hidup Bersih dan Sehat (PHBS) dan menciptakan lingkungan yang saniter dapat memberikan pemahaman yang mendalam dan komprihensif mengenai bagaimana mewujudkan PHBS dalam kehidupan sehari-sehari serta menjaga kelestarian lingkungan tanpa membuat pencemaran lingkungan. Hal ini terlihat dari masyarakat peserta yang banyak mengajukan pertanyaan yang berkaitan dengan kesehatan dan menciptakan lingkungan hidup yang saniter serta berkomitmen untuk mengimplemen-tasikan PHBS dan mewujudkan lingkungan yang saniter. Tersedianya akses air bersih dari 2 unit sumur bor dengan kualitas baik yaitu tidak berwarna, tidak berbau dan tidak berasa untuk 20 KK di Kampung Khaidir Lingkungan 6 Kelurahan Nelayan Indah Kecamatan Medan Labuhan.

Adapun yang menjadi saran adalah : Pelatihan pemanfaatan sampah rumah tangga menjadi pelet pakan ternak dan barang komoditi yang meningkatkan pendapatan keluarga.

\section{UCAPAN TERIMAKASIH}

Artikel ini merupakan salah satu hasil dari Program Pengabdian kepada Masyarakat yang Dibiayai oleh dana NON PNBP Universitas Sumatera Utara. Oleh karena itu, diucapkan terima kasih kepada Rektor Universitas Sumatera Utara atas dukungan dana dan fasilitas yang diberikan. Terima kasih juga kepada Mitra pada kegiatan pengabdian ini.

\section{DAFTAR PUSTAKA}

Ashar,T, Santi,D.N, \& Naria E. 2013. Kromium, Timbal dan merkuri dalam Air Sumur Masyarakat di Sekitar Tempat Pembuangan Akhir Sampah, Kesmas Jurnal Kesehatan Masyarakat Nasional

Departemen Kesehatan RI, 2009. Rumah Tangga Sehat dengan Prilaku Hidup Bersih dan Sehat. (Booklet)

FK UNS, 2013. Prilaku Hidup Bersih dan Sehat (Modul Field Lab). Mahyudi, 2010, Perbedaan Penurunan Kadar Besi (Fe) Pada Air Sumur Dengan Cara Aerasi Bertingkat, Aerator, Dan Oksidator (KMnO4) Tahun 2010 (Skripsi) Medan Universitas Sumatera Utara. 
Omposunggu, H, 2009. Analisa Kandungan Nitrat Air Sumur Gali Masyarakat Di Sekitar Tempat Pembuangan Akhir (TPA) Sampah Di Desa Namo Bintang Kecamatan Pancur Batu Kabupaten Deli Serdang tahun 2009 (Skripsi), Medan Universitas Sumatera Utara.

Sinamo, 2016. Efektivitas Aplikasi Saringan air dengan Penggunaan Media Pasir, Karbon Aktif dan Zeolit untuk Penurunan Kadmium pada Air Sumur Gali Masyarakat Desa Namo Bintang Tahun 2015 (Skripsi), Medan Universitas Sumatera Utara.

Wastina,S, 2011. Gambaran Perilaku Mayarakat Tentang Konstruksi Sumur Gali Dan Kualitas Air Di Desa Gunung Raya Kabupaten Labuhan Batu Rantau Prapat Tahun 2010 (Skripsi), Medan Sumatera Utara.

Nurwahidah, I. 2017. Gambaran program Prilaku Hidup Bersih dan Sehat Tatanan Rumah Tangga di Puskesmas Balaraja Kabupaten Tanggerang Tahun 2017 (Skripsi), Jakarta, Universitas Islam Negeri Syarif Hidayatullah. 13 